\title{
Entgegnung auf vorstehende Bemerkung
}

\author{
von Dr. Jaffé und Dr. Besserer.
}

$\mathrm{Zu}$ der vorstehenden Erklärung bemerken wir folgendes:

1. Die von uns in No. s̃ dieser Wochenschrift mitgeteilten Tatsachen sind gänzlich unabhängig und ohne Kenntnis der von Friedberger und Moreschi ausgeführten Arbeiten bereits ror Jahresfrist festgestellt worden. Durch mündiche Mitteilung des Herrn Prof. Kolle waren die Herren Friedberger und Moreschi bereits vor Drucklegung ihrer Veröffentlichungen von dieser Sachlage unterrichtet.

2. Trotzdem ist von uns das Recht der früheren Publikation Friedbergers und Moreschis durch den in einer Fußnote enthaltenen Hinweis auf ihre Arbeit gewahrt worden. Die Erhebung ron Prioritatsansprüchen seitens Friedbergers war also ebenso unnotig wie die wenig freundliche Bemerkung Friedbergers am Schlusse seiner Entgegnung.

3. Auf die wissenschaftliche Seite der Frage, namentlich auch ob der Stamm Sprung, auf dessen Verhalten allein Friedberger und Moreschi ihre Schlubfolgerungen aufbauen, ïberhaupt ein echter Typhusstamm ist, werden wir in einer späteren Arbeit eingehen. 